UDC 1:7:001.91

LBC 87.822.222

\title{
FORMING A CULTURE-CENTRIC IMAGE OF RUSSIA THROUGH METAPHORICAL FRAMING ${ }^{1}$
}

\author{
Tatyana S. Gorina \\ Volgograd State University, Volgograd, Russian Federation
}

\begin{abstract}
The paper analyzes the opportunities of applying metaphorical framing in constructing a culturecentric image of Russia. Methodologically it relies on the conceptual metaphor theory elaborated by G. Lakoff and M. Johnson, according to which metaphor is a fundamental cognitive mechanism and enables us to understand and structure a more complex abstract target domain in terms of a more concrete familiar and embodied source domain. Metaphors perform a function of a framing tool: they establish frames and boundaries of human understanding of the world around; focus our attention on a posed problem; affect a recipient's attitude to phenomena, personalities, events foregrounding some the features of a target domain while overshadowing others. In this connection, by applying metaphorical framing one can single out certain aspects of the Russian reality making them salient, either appealing or repulsive, components of the Russian image. Metaphorical frames also enable to disguise some aspects of reality, thus constructing positive or negative attitudes to the country. The study emphasizes that, although the image of Russia within and outside the country is commonly constructed by referring to its political position, economic climate, its negative aspects do not seem to affect the attitudes to the Russian culture, and its development is seen as a process unfolding contrary to the current situation. The cultural component in the image of Russia is currently expressed vaguely, yet some research findings show a high potential for its application in constructing a positive image of Russia, including through metaphorical framing. Promoting a culturecentric image of Russia is possible through employing a range of metaphors such as Russia is a Spring, Russia is a Family and Russia is a Book. The paper concludes that metaphors tuned to the Russian culture will contribute to a change in the deeply rooted negative stereotypes about Russia, to constructing a modern, stable positive image of Russia comprehensible both within and outside the country. Metaphors are capable of stressing the country's openness to interacting with other peoples, its willingness and interest in cooperating with them.
\end{abstract}

Key words: metaphor, image of Russia, framing, culture, constructing the image of Russia.

Citation. Gorina T.S. Forming a Culture-Centric Image of Russia Through Metaphorical Framing. Logos et Praxis, 2021, vol. 20, no. 1, pp. 58-64. (in Russian). DOI: https://doi.org/10.15688/lp.jvolsu.2021.1.7

УДК 1:7:001.91

ББК 87.822 .222

\section{ФОРМИРОВАНИЕ КУЛЬТУР-ЦЕНТРИЧНОГО ОБРАЗА РОССИИ МЕТОДОМ МЕТАФОРИЧЕСКОГО ФРЕЙМИНГА ${ }^{1}$}

\author{
Татьяна Сергеевна Горина \\ Волгоградский государственный университет, г. Волгоград, Российская Федерация
}

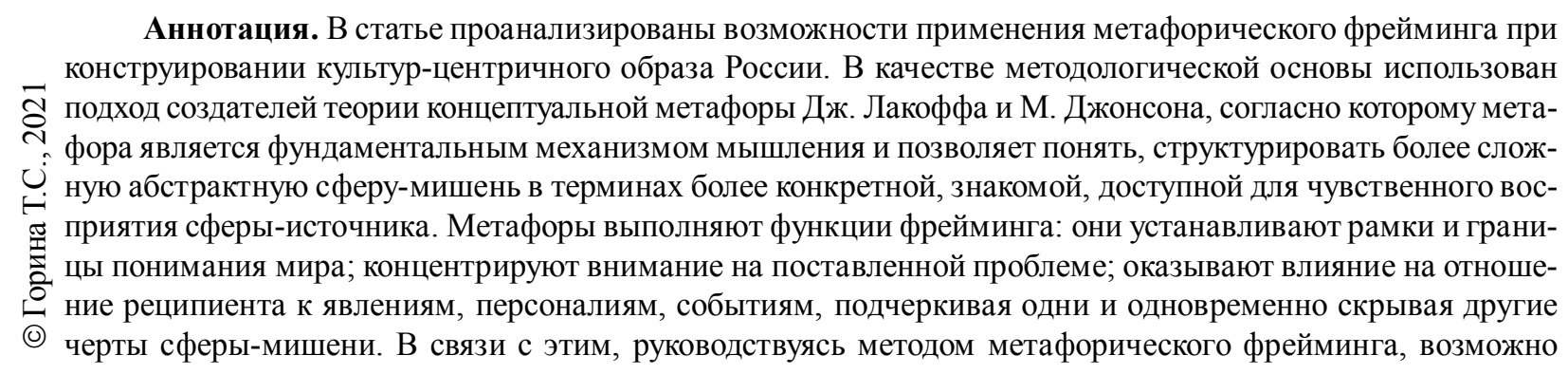


выделить определенные аспекты российской действительности, сделав их существенными, в том числе привлекательными или отталкивающими, компонентами образа России, а также замаскировать иные параметры, формируя таким образом позитивное или негативное восприятие нашей страны. Отмечается, что, хотя образ России внутри страны и за ее пределами часто формируется посредством обращения к политическому положению, экономической обстановке, его негативные аспекты практически не влияют на отношение к культуре России, развитие которой воспринимается как процесс, происходящий вопреки сложившейся ситуации. Культурный компонент в образе России в настоящее время выражен слабо, однако результаты исследований демонстрируют высокий потенциал его использования при конструировании образа страны, в том числе методом метафорического фрейминга. Создание культур-центричного образа России возможно при помощи широкого спектра метафор, среди которых «Россия - родник», «Россия - семья» и «Россия книга». Сделан вывод о том, что метафоры, ориентированные на культуру России, будут способствовать изменению сложившихся о стране негативных стереотипов, формированию современного, устойчивого, понятного как внутри России, так и за ее пределами положительного образа, подчеркнут открытость страны к взаимодействию с другими народами, заинтересованность в сотрудничестве с ними.

Ключевые слова: метафора, образ России, фрейминг, культура, конструирование образа России.

Цитирование. Горина Т. С. Формирование культур-центричного образа России методом метафорического фрейминга // Logos et Praxis. - 2021.- T. 20, № 1. - C. 58-64. -DOI: https://doi.org/10.15688/lp.jvolsu.2021.1.7

Несмотря на многолетнюю историю международных отношений, включающую взаимодействие по вопросам поддержания мира и безопасности, укрепления демократических институтов, защиты прав и интересов российских граждан и соотечественников, проживающих за рубежом, Россия по-прежнему воспринимается во многих государствах как загадочная, непредсказуемая и чужеродная страна. Стремление России упрочить свои позиции на мировой арене путем развития межнационального диалога и сотрудничества обусловливает важность задачи формирования ее современного, понятного и привлекательного образа. Высокий авторитет России в сфере культуры и искусства, где, в отличие от политики, ее репутация не обременена отрицательными стереотипами, в сочетании с желанием усилить и расширить влияние российской культуры, имеющей богатые традиции и динамично развивающейся в настоящее время, актуализирует конструирование культур-центричного образа России, в том числе при помощи метафорического фрейминга.

Создатели теории концептуальной метафоры Дж. Лакофф и М. Джонсон изменили традиционные представления о метафоре как стилистическом средстве, предложив рассматривать ее как фундаментальный механизм мышления, «способ постижения одной вещи в терминах другой» [Лакофф, Джонсон 2004, 62]. Метафора выражает, фиксирует связи между иногда очень различными концептуальными сферами. Благодаря метафоре более сложная абстрактная сфера-мишень структурируется и понимается в терминах более конкретной, знакомой, доступной для чувственного восприятия сферы-источника.

Метафоры выполняют функции фрейминга, обозначенные Р. Энтманом: «выбор и выделение некоторых аспектов событий или проблем и установление связей между ними для продвижения конкретной интерпретации, оценки и/или решения» [Entman 2004, 5]. Они помогают людям понять мир, задавая рамки, границы такого понимания, обращают внимание на поставленную проблему, формируя отношение реципиента к явлениям, персоналиям, фактам, подчеркивая одни и одновременно скрывая другие черты сферы-мишени. В связи с этим при помощи метафорического фрейминга возможно выделить определенные аспекты российской действительности, сделав их существенными, значимыми, в том числе привлекательными или отталкивающими, компонентами образа России, а также замаскировать другие параметры, формируя таким образом позитивное или негативное восприятие нашей страны.

Вопросы, касающиеся образа России, неоднократно рассматривались в научной литературе. Однако его культурная составляющая как объекта метафорического фрейминга исследуется редко, хотя именно она соответствует представлениям, согласно которым «в современном мире культура становится значимым ресурсом социально-экономического развития, позволяющим обеспечить лидиру- 
ющее положение нашей страны в мире» [Указ Президента от 24.12.2014 № 808... web]. О целесообразности обращения к культуре свидетельствуют активное участие музеев в различных проектах для «создания образа России как невероятной, многосложной, богатейшей культурной цивилизации» [Зельфира Трегулова... web]; пресс-туры по России, организуемые для журналистов и блогеров из разных государств для того, чтобы познакомить их с современной российской культурой и сформировать положительное отношение к нашей стране [Образ России web].

Значительное воздействие на восприятие России оказывает степень информированности о ней представителей различных социальных групп. Так, если образ России в обыденном сознании граждан Германии является негативным, то немецкая научная интеллигенция относится к ней с уважением [Дейнека, Медяник 2020]. Образ нашей страны, сформированный в сознании иностранных студентов, обучающихся в России, в целом положительный, отличается от негативного стереотипного образа, транслируемого некоторыми зарубежными СМИ, и даже более позитивный, чем сложившийся у российских студентов [Дейнека, Кузнецова 2020]. Каналами формирования образа России выступают телевидение, интернет, образовательные учреждения, СМИ, книги, фильмы, семья, родственники, общение с россиянами, личный визит в РФ и т. п.

Несмотря на низкую осведомленность граждан других государств о России, во многих странах существует высокий запрос на знакомство с ее культурой. «Русская культура», согласно данным 2017 г., интересна $43 \%$ жителей Республики Корея и ассоциируется в первую очередь (35\% респондентов) с искусством (балет / танец, литература, писатели, музыка, кукла), особое внимание привлекают архитектура и кухня [Баскакова, Чой Ву Ик web]. На вопрос о том, что граждане Турции хотели бы перенять из культуры России, опрошенные Е.В. Бахревским турецкие эксперты (39 чел.) чаще всего отвечали «высокая культура» (также ими отмечались искусство, литература, музыка, образование, наука, балет) [Бахревский web]. Россияне относят историю, культуру, язык к сильным сторонам нашей страны, больше всего они гордятся историей [Селезнева, Палитай 2019]. Явления культуры не выступают ключевыми компонентами, вокруг которых у российских студентов формируется представление о Родине, однако, когда они испытывают за нее гордость, предметом последней чаще всего становится культура [Малышева, Стефаненко, Тихомандрицкая 2012]. Хотя культурный компонент в образе России пока выражен слабо, результаты исследований демонстрируют высокий потенциал его использования при формировании образа страны, одним из инструментов которого выступает метафорический фрейминг.

Можно выделить несколько основных концептуальных моделей метафоризации: пространственную, натуралистическую, социальную и артефактную [Балашова 2014; Балашова 2017; Балашова 2020]. Первая предполагает репрезентацию непредметного мира через пространственную систему координат. В рамках второй модели происходит осмысление непредметной сферы через обращение к физическим особенностям неживых и живых объектов, «через восприятие мира органами чувств и оценку внешнего мира с точки зрения благоприятных или неблагоприятных для жизнедеятельности человека условий» [Балашова 2014, 80]. Она включает в качестве наиболее распространенных и продуктивных антропоморфную, зооморфную, флористическую модели. Социальная модель «объединяет метафоры, репрезентирующие непредметный мир как определенную социальную модель, связанную с жизнью человека в обществе, различными типами его хозяйственной, созидательной, общественной и культурной деятельности» [Балашова 2014, 80]. В ее состав входят, например, социально-иерархическая, экономическая, военная, состязательная (спортивная) модели. Согласно артефактной модели непредметный мир ассоциируется с созданными и используемыми человеком объектами (механизмами, агрегатами, инструментами, зданиями, пищей и т. п.).

Образ России внутри страны и за ее пределами часто создается через обращение к политической ситуации (коррупция, особенности формы правления, судебной системы, отношения с другими государствами и т. п.), ее экономическому положению (динамика ВВП, 
платежный баланс, бюджетная политика и др.). Малая информированность о России в некоторых случаях компенсируется использованием популярных, часто повторяющихся метафор, отражающих мифы, стереотипы и формирующих крайне расплывчатый и противоречивый образ нашей страны.

Такими являются, например, зооморфные метафоры. Россия, как правило, ассоциируется с диким животным: медведем, змеей, ежом, орлом. Метафора «Россия - еж» обращает внимание на агрессивную внешнюю политику страны, которая защищает свои интересы, территорию, существует обособленно, может объединяться с другими государствами, однако есть пределы такого сближения, преодоление которых опасно негативным воздействием РФ на партнера [Солопова, Будаев, Бойко 2020]. Образ нашей страны, формируемый метафорой «Россия - медведь», не столь однозначный. Такое отождествление дает основание для ассоциации России со злом и опасностью, так как медведь - животное крупное, неуклюжее, страшное, сердитое, свирепое, страдающее, на него трудно охотиться, его сложно приручить. При этом данная метафора подчеркивает силу духа русского народа, авторитет и мощь страны, ведь медведь может быть улыбчивым, белым, пушистым, гордым, смелым, готов постоять за себя, дать отпор неприятелю. Примечательно, что негативные аспекты политического, экономического образа России практически не влияют на отношение к ее культуре, развитие которой воспринимается как процесс, происходящий вопреки сложившейся ситуации.

Формирование культур-центричного образа России возможно при помощи широкого спектра метафор, среди которых «Россия - родник», «Россия - семья» и «Россия книга».

Родник - это «естественный выход подземных вод на земную поверхность на суше или под водой на дне континентальных водоемов и водотоков... морей» [Трёшников (ред.) $1988,117]$, «водяной источник, текущий из глубины земли, ключ» [Ожегов 2014, 549]. Пространственная метафора «Россия - родник» соответствует закрепившемуся в сознании россиян и граждан других государств обращению к прошлому при восприятии России и показывает связь прошлого с современной российской действительностью. Метафора также обращает внимание на уникальность, самобытность культуры России, отмечает, что она выступает в качестве консолидирующего начала российского общества. При помощи данной метафоры может быть создан образ нашей страны как центра истории и культуры мирового значения.

Частота ассоциаций России с именами писателей, поэтов, литературными произведениями делает эффективной и узнаваемой артефактную метафору «Россия - книга», подчеркивающую ценность, авторитет, сложность и разнообразие культуры России, уникальность ее создателей, привлекающую внимание к русскому языку, способам его изучения. Такая метафора усиливает позитивную составляющую образа России, формируя представление о ней, как о стране, в которой происходят интересные события, разворачивается насыщенная культурная жизнь, созданы условия для того, чтобы заниматься творчеством, проявлять свой талант, достигать поставленных целей.

Различные трактовки понятия «семья» «группа людей, состоящая из мужа, жены, детей и других близких родственников, живущих вместе», «группа людей, сплоченных общей деятельностью, интересами, дружбой» [Кузнецов (ред.) 2000, 1175] - позволяют указать на культурное своеобразие нашей страны, взаимодействие, взаимовлияние ее многочисленных народов, возможность продуктивного сотрудничества с носителями различных ценностей путем применения социальной метафоры «Россия - семья». Она также подчеркивает значимость накопленного прошлыми поколениями исторического и культурного опыта, вызывает интерес к культуре современной России.

Метафоры, ориентированные на культуру России, будут способствовать изменению сложившихся о стране негативных стереотипов, формированию современного, устойчивого, понятного внутри России и за ее пределами положительного образа. Использование таких метафор позволит реципиенту не просто быть сторонним наблюдателем происходящего в стране, но и понимать людей, которые в ней живут. Учитывая зависимость восприятия России от имеющихся о ней знаний, 
возможно повысить эффективность метафорического фрейминга при условии расширения информационного поля, в котором он применяется, в том числе за счет обеспечения максимально полного и быстрого доступа к культуре нашей страны, русскому языку, языкам народов России.

Неоднозначность, противоречивость образа России предоставляют возможность для его успешного изменения в положительную сторону методом метафорического фрейминга. Распространение, популяризация культуры России как неотъемлемой части мировой культуры позволит создать образ страны, открытой к взаимодействию с другими народами, заинтересованной в сотрудничестве с ними. Превращение историко-культурного наследия России в один из основных ресурсов формирования ее позитивного образа сделает страну привлекательной, интересной как для россиян, так и для граждан других государств.

\section{ПРИМЕЧАНИЕ}

${ }^{1}$ Исследование выполнено при финансовой поддержке РФФИ и ЭИСИ в рамках научного проекта № 20-011-31715 «Стратегии конструирования образа России методом образного фрейминга».

The reported study was funded by RFBR and EISR according to the research project no. 20-011-31715 "Strategies of constructing the image of Russia through figurative framing".

\section{СПИСОК ЛИТЕРАТУРЫ}

Балашова 2014 - Балашова Л.В. Русская метафора: прошлое, настоящее, будущее. М.: Языки славянской культуры, 2014.

Балашова 2017 - Балашова Л.В. Экономика России в современном политическом дискурсе сквозь призму концептуальной метафоры // Политическая лингвистика. 2017. № 1 (61). С. 21-30.

Балашова 2020 - Балашова Л.В. Речевая метафора как способ репрезентации образа России в современных оппозиционных массмедиа // Политическая лингвистика. 2020. № 3 (81). C. 23-38. DOI: https://doi.org/10.26170/p120-03-02. Баскакова, Чой Ву Ик wеb - Баскакова Ю.М., Чой Ву Ик. Россия и Корея: Образ стран по данным сравнительного исследования // https://book.wciom.ru/ fileadmin/file/books/rus_kor2018.pdf.
Бахревский web - Бахревский Е.В. Современный образ России и русских в Турции [Культурологический журнал. 2018. № 1 (31)] // http://crjournal.ru/rus/journals/428.html\&j_id=34.

Дейнека, Кузнецова 2020 - Дейнека О.С., Кузнеиова Ю.С. Образ России у иностранных студентов в контексте международного гуманитарного сотрудничества // Ананьевские чтения 2020. Психология служебной деятельности: достижения и перспективы развития (в честь 75-летия Победы в Великой Отечественной войне 1941-1945 гг.): материалы междунар. науч. конф. (г. Санкт-Петербург, 8-11 дек. 2020 г.). СПб.: Скифия-принт, 2020. С. 405-406.

Дейнека, Медяник 2020 -Дейнека О.С., Медяник С.И. Образ-представление России в обыденном сознании немецких граждан // Ананьевские чтения - 2020. Психология служебной деятельности: достижения и перспективы развития (в честь 75-летия Победы в Великой Отечественной войне 1941-1945 гг.): материалы междунар. науч. конф. (г. Санкт-Петербург, 8-11 дек. 2020 г.). СПб.: Скифия-принт, 2020. С. 407-408.

Зельфира Трегулова... web - Зельфира Трегулова, генеральный директор Государственной Третьяковской галереи [Панельная дискуссия «Русский мир онлайн»] // https://www.youtube.com $/$ watch? $=7 \mathrm{wgHL} 5 \mathrm{meIw} 4 \&$ feature $=$ youtu.be .

Кузнецов (ред.) 2000 - Кузнеиов С.А. (ред.). Большой толковый словарь русского языка. СПб.: Норинт, 2000.

Лакофф, Джонсон 2004 - Лакофф Дж., Джонсон М. Метафоры, которыми мы живем. М.: Едиториал УРСС, 2004.

Малышева, Стефаненко, Тихомандрицкая 2012 Мальшева Н.Г., Стефаненко Т.Г., Тихомандриикая O.A. Образ России в многополярном мире: кросс-культурный анализ // Вестник Московского университета. Серия 14. Психология. 2012. № 1. С. 61-72.

Образ России web-Образ России // http://amcult.ru/ image-of-russia.

Ожегов 2014 - Ожегов С.И. Толковый словарь русского языка. Ок. 100000 слов, терминов и фразеологических выражений. М.: АСТ: Мир и образование, 2014.

Селезнева, Палитай 2019 - Селезнева А.В., Палитай И.С. Восприятие своей страны российской молодежью: ценностно-символический и политико-культурный аспекты // Научно-технические ведомости СПбГПУ. Гуманитарные и общественные науки. 2019. Т. 10, № 2. С. 123 135. DOI: https://doi.org/10.18721/JHSS.10211.

Солопова, Будаев, Бойко 2020 - Солопова, О.А., Будаев Э.В., Бойко А.В. Метафорический образ будущего России в неинституциональном по- 
литическом интернет-дискурсе КНР // Политическая лингвистика. 2020. №6 (84). С. 96-107. DOI: https://doi.org/10.26170/pl20-06-10.

Трёшников (ред.) 1988 - Трёшников А.Ф. (ред.). Географический энциклопедический словарь. Понятия и термины. М.: Советская энциклопедия, 1988.

Указ Президента от 24.12.2014 № 808... web - Указ Президента РФ от 24.12.2014 № 808 «Об угверждении Основ государственной культурной политики» // http://base.garant.ru/70828330.

Entman 2004 - Entman R.M. Projections of Power: Framing News, Public Opinion, and US Foreign Policy. Chicago: University of Chicago Press, 2004.

\section{REFERENCES}

Balashova L.V., 2014. Russian Metaphor: Past, Present, Future. Moscow, Yazyki slavyanskikh kul'tur Publ.

Balashova L.V., 2017. The Russian Economy in Modern Political Discourse Through the Prism of a Conceptual Metaphor. Political Linguistics, no. 1 (61), pp. 21-31.

Balashova L.V., 2020. Genuine Metaphor as a Way of Representing Russia's Image in Modern Opposition Mass Media. Political Linguistics, no. 3 (81), pp. 23-38. DOI: https://doi.org/ 10.26170/pl20-03-02.

Baskakova J.M., Choi Woo Ik. Russia and Korea: Country Image According to a Comparative Study. URL: https://book.wciom.ru/fileadmin/ file/books/rus_kor2018.pdf.

Bakhrevsky E.V., 2018. The Modern Image of Russia and Russians in Turkey. Journal of Cultural Research, no. 1 (31). URL: http://cr-journal.ru/ rus/journals/428.html\&j_id=34.

Deyneka O.S., Kuznetsova Y.S, 2020. Foreign Students' Image of Russia in Context International Humanitarian Cooperation. Ananiev Readings 2020. Psychology of Military, Enforcement and Governmental Services: Achievements and Development Prospects (In Honor of the $75^{\text {th }}$ Anniversary of the Victory in the Great Patriotic War of 1941-1945): Materials of the International Scientific Conference, December 8-11, 2020. Saint Petersburg, Skifiya-print Publ., pp. 405-406.

Deyneka O.S., Medyanik S. I., 2020. The ImageRepresentation of Russia in the Everyday
Consciousness of German Citizens. Ananiev Readings - 2020. Psychology of Military, Enforcement and Governmental Services: Achievements and Development Prospects (In Honor of the $75^{\text {th }}$ Anniversary of the Victory in the Great Patriotic War of 1941-1945): Materials of the International Scientific Conference, December 8-11, 2020. Saint Petersburg, Skifiya-print Publ., pp. 407-408.

Zelfira Tregulova, General Director of The State Tretyakov Gallery. Panel Discussion "Russian World Online”. URL: https://www.youtube.com/ watch? $\mathrm{v}=7 \mathrm{wgHL} 5 \mathrm{meIw} 4 \&$ feature=youtu.be.

Kuznetsov S.A. (ed.), 2000. Great Dictionary of Russian Language. Saint Petersburg, Norint Publ.

Lakoff G., Johnson M., 2004. Metaphors We Live by. Moscow, Editorial URSS Publ.

Malysheva N.G., Stefanenko T.G., Tikhomandritskaya O.A., 2012. The Image of Russia in a Multipolar World: Cross-Cultural Analysis. The Moscow University Herald. Series 14. Psychology, no. 1, pp.61-72.

The Image of Russia. URL: http://amcult.ru/image-ofrussia.

Ozhegov S.I., 2014. Explanatory Dictionary of the Russian Language. About 100,000 Words, Terms and Phraseological Expressions. Moscow, AST Publ., Mir i obrazovanie Publ.

Selezneva A.V., Palitay I.S., 2019. Russian Youth's Perception of Their Country: Value-Symbolic and Political-Cultural Aspects. St. Petersburg State Polytechnical University Journal: Humanities and Social Sciences, vol. 10, no. 2, pp. 123-135. DOI: https://doi.org/10.18721/JHSS.10211.

Solopova O.A., Budaev E.V., Boiko A.V., 2020. Metaphorical Image of the Future of Russia in the Chinese Non-Institutional Political Internet Discourse. Political Linguistics, no. 6 (84), pp. 96-107. DOI: https://doi.org/10.26170/pl2006-10.

Treshnikov A.F. (ed.), 1988. Geographical Encyclopedic Dictionary. Concepts and Terms. Moscow, Sovetskaya enciklopediya Publ.

Decree of the President of the Russian Federation of December 24, 2014 no. 808 "On Approval of the Fundamentals of State Cultural Policy”. URL: http://base.garant.ru/70828330.

Entman R.M., 2004. Projections of Power: Framing News, Public Opinion, and US Foreign Policy. Chicago, University of Chicago Press. 


\section{Information About the Author}

Tatyana S. Gorina, Candidate of Sciences (Philosophy), Associate Professor, Department of Philosophy, Volgograd State University, Prosp. Universitetsky, 100, 400062 Volgograd, Russian Federation, gorina@volsu.ru, https://orcid.org/0000-0001-5114-1821

\section{Информация об авторе}

Татьяна Сергеевна Горина, кандидат философских наук, доцент кафедры философии, Волгоградский государственный университет, просп. Университетский, 100, 400062 г. Волгоград, Российская Федерация, gorina@volsu.ru, https://orcid.org/0000-0001-5114-1821 